\title{
Using Community-Based Social Marketing to Improve Energy Equity Programs ${ }^{1}$
}

\author{
Marianne Schmink, Emily Ott, Paul Monaghan, Lee Hayes Byron, Alane Humrich, Jennison \\ Kipp, Wendell Porter, Matthew Williams, Kimberly Davis and Fiona Hogan²
}

\section{Introduction}

This publication is part of a series that will help Extension agents, nonprofits, agency personnel and all types of community development practitioners to better understand the issue of high utility bills among low-income residents, the "energy equity gap" and what they can do to help. The first publication (https://edis.ifas.ufl.edu/publication/WC368) provided an overview of one program approach taken by a group of volunteers in Alachua County, Florida, the Community Weatherization Coalition (CWC), which uses a model of trained "energy coaches." Other publications in the series will provide details on how a similar Extension program can be implemented in any community, using a step-by-step guide, with evaluation tools for calculating energy savings and measuring impacts on clients and volunteers. This document provides a description of how the CWC used Community-Based Social Marketing (CBSM) research to increase the impact of their program through a form of "action research" to guide practical changes. Their experience can provide useful lessons for Extension agents and all types of community development practitioners who are seeking to improve the impacts of their programs.

\section{Community-Based Social Marketing (CBSM) Research}

CBSM offers a framework of traditional marketing concepts to help organize information and identify specific opportunities to make behavior change programs more effective in achieving results (McKenzie-Mohr \& Smith, 1999; Thomson \& Brain, 2016; US Dept. of Energy, 2017). These marketing concepts include identifying target audiences, understanding their perceived benefits and barriers to change, and then developing interventions at the place where change occurs using appropriate communications methods for the audiences. At the core, CBSM is a method of listening to program participants, analyzing the components and steps of behavior change, and consciously attempting to increase the benefits offered for change, while lowering the barriers to make change easier. One of the major assumptions of CBSM is that the clients of a program are the experts in how and what will influence them to participate and perform behaviors recommended by the program. To make a program work or work more effectively, it is very important to talk with and listen to the clients and potential clients as an "audience." To help change agents become familiar with the approach

1. This publication is AEC746, one of a series of the Department of Agricultural Education and Communication, UF/IFAS Extension. Original publication date February 2022. Visit the EDIS website at https://edis.ifas.ufl.edu for the currently supported version of this publication.

2. Marianne Schmink, professor emerita, Latin American studies; Emily Ott, research coordinator, Department of Agricultural Education and Communication; Paul Monaghan, associate professor, Extension education, Department of Agricultural Education and Communication; Lee Hayes Byron, county Extension director and program Extension agent II, UF/IFAS Extension Sarasota County; Alane Humrich, program director, Community Weatherization Coalition; Jennison Kipp, Sustainable Floridians state coordinator, Program for Resource Efficient Communities; Wendell Porter, senior lecturer, Department of Agricultural and Biological Engineering; Matthew Williams, director, UF Office of Sustainability; Kimberly Davis, Extension agent, Florida A\&M University Cooperative Extension; and Fiona Hogan, strategic projects manager, UF Office of Sustainability; UF/IFAS Extension, Gainesville, FL 32611.

The Institute of Food and Agricultural Sciences (IFAS) is an Equal Opportunity Institution authorized to provide research, educational information and other services

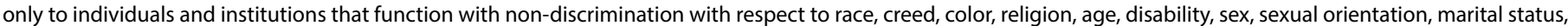

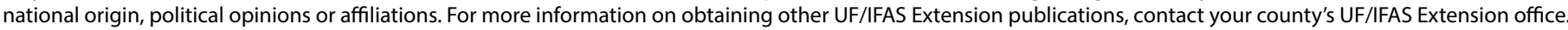
U.S. Department of Agriculture, UF/IFAS Extension Service, University of Florida, IFAS, Florida A \& M University Cooperative Extension Program, and Boards of County Commissioners Cooperating. Andra Johnson, dean for UF/IFAS Extension. 
and methods of CBSM, a number of introductory EDIS documents have been produced, such as Community-Based Social Marketing (CBSM: Extension's New Approach to Promoting Environmental Behavior Change (https://edis. ifas.ufl.edu/publication/WC119) and Using Social Norms to Increase Behavior Change in Sustainable Landscaping (https://edis.ifas.ufl.edu/publication/WC158).

\section{Community Weatherization Coalition (CWC)}

The Community Weatherization Coalition (https://communityweatherization.org/) is a partnership of organizations and individuals in Alachua County, Florida that includes the faith community, the University of Florida (UF), the publicly owned regional utility (Gainesville Regional Utilities, or GRU), local government, and several nonprofit groups. They have worked together since 2008 to train and deploy energy "coaches" to carry out comprehensive home energy and water audits or "tune-ups" in low-income homes. Thirteen years later, in 2021, CWC energy coaches have carried out over 1,250 home energy/water audits and saved residents hundreds of thousands of dollars in local utility bills, over seven million gallons of water, and over two million kilowatt-hours of electricity.

Despite these successes, potential pitfalls are highlighted in literature on home energy/water audits and retrofits for low-income households that show a tendency toward low participation rates, minimal behavior change, and disappointing energy savings per return on investment (Abrahamse et al., 2005; Reames, 2016). This CBSM project addressed these potential problems through a team approach involving a local utility (GRU), researchers at the University of Florida, and the CWC, working together in targeted neighborhoods with other local partner organizations. The goals were to evaluate and improve program activities and communications materials, focus on specific conservation barriers, and find strategies to lower them. These changes were intended to increase CWC program participation, including client applications, but also to increase the number of volunteers trained and help them become active volunteers.

The CBSM research was planned and carried out with the full participation of CWC staff, volunteers, and partners, using an applied approach that sought to implement changes throughout the organization and its procedures and activities. The research built on pillars of predefined strategic planning priorities and the commitment to a community-based strategy embedded in a strong collaboration with a particular neighborhood. Research activities included a neighborhood survey, focus groups with CWC stakeholders (volunteers and clients), participant observation of training and of the home audit process and finally, follow-up surveys with clients.

\section{Community-Based Strategy}

In order for CBSM programming to be successful, change agents must be strong and consistent partners in the targeted community, with an emphasis on building trusting relationships. Since 2016, members of the CWC have been attending meetings of a group of partner organizations, led by Alachua Habitat for Humanity, working together as part of the Greater Duval Neighborhood Revitalization Initiative. A Duval neighborhood Community Advisory Board was created in 2016 to support the CWC's energy- and money-saving programs. A grassroots community group, the Greater Duval Neighborhood Association (GDNA) was formalized as a neighborhood service organization in 2017, and the CWC focused social research efforts in the Duval neighborhood, where it was possible to work with the GDNA to recruit research participants as well as clients. Duval and other neighborhoods targeted by the CWC are primarily composed of low-income, historically marginalized racial groups such as African-American and Latinx families who live in older houses that typically have older, inefficient energy systems. This leads to inequality in the percentage of monthly income that is spent on energy costs and higher relative utility bills, even though these households use less overall energy when compared with others in the county. This is called the "energy equity gap," when one segment of a population has a disproportionate burden of utility costs due to poverty and home construction. CWC energy audit clients include homeowners and renters, single mothers with young children, families and the elderly (40\% of Greater Duval's population) who are aging in place and living on fixed incomes, including many veterans.

The CWC supported GDNA with funds to hire and train young people from the Duval neighborhood to conduct a survey of community needs, including a question that assessed interest in receiving CWC's home energy and water tune-up services. This support helped the team to build trust and goodwill and provided CWC with a list of potential clients in the target neighborhood, several of whom later became clients. The research partnership continued as some GDNA board members served as advisors and helped recruit focus group participants for later stages of research. Once the focus group data had been collected and marketing strategies had been developed, the research team also developed a presentation to share results with focus group 
participants and community advisory board members, GDNA board members, CWC board members, and other stakeholders.

The partnership paid off in program success. Home energy/ water tune-ups carried out in 103 homes in the Greater Duval neighborhood over the past 10 years resulted in an average savings of $\$ 313$ in utility expenses per home during the subsequent year. Multiplied by 103 homes, this figure suggests that Duval residents saved approximately $\$ 32,239$ in utility expenses each subsequent year due to CWC tune-ups. With annual savings repeated in the years following a tune-up, the return through energy savings eventually exceeds the cost of implementing the program. CWC's partnership efforts and the observed program impact of CWC tune-ups contributed to the Greater Duval Neighborhood Association awarding the CWC "Favorite Partner" in 2017.

\section{Using Focus Groups to Improve Programming}

Focus groups can play an important role in understanding how programs are seen by clients and what barriers might exist to program success. Focus groups were designed to collect information from volunteers, clients and potential clients that could be used to improve the program. A total of five focus groups were conducted in the summer of 2016: two with volunteer auditors and three with clients and potential clients. With the help of a CBSM coordinator, the CWC used the data to brainstorm possible changes to the program and the communications materials. The goals of the focus groups were to

- Uncover benefits and barriers to getting a home energy/ water audit, adopting conservation behaviors and being an active volunteer;

- Discover appropriate communication channels, content and strategy for clients and for volunteer recruitment;

- Improve recruitment and increase the number of audits performed by volunteers;

- Increase utility savings of audited households, incorporating insights from CBSM to improve the audit process; and

- Increase volunteer training enrollment and volunteer activity.

\section{Changing Communications Messages}

The focus group research with actual clients and potential clients of CWC services revealed that calling the home energy efficiency service an "audit" caused clients to be wary, skeptical and even scared of the program. Potential clients said they might be embarrassed to have strangers judging their energy situation, which they already realize has problems (aging appliances, leaks, outdated HVAC systems). With this insight, CWC was able to work on new, better-received messaging. With focus group data from volunteers, clients and potential clients in hand, program decision makers decided to change messaging and for several elements of CWC's services and to emphasize the co-learning that takes place among clients and volunteers:

- Change the term "Audit" to the friendlier and less threatening term "Home Energy Tune-up."

- Change the term "Auditor" to "Volunteer Energy Coach" or "Energy Coach."

- Intentionally use "client" and "resident" and no longer use "homeowner" to describe the people who are served by CWC, to make it clear that renters as well as homeowners are eligible.

- Clearly state that the CWC "tune-ups" can result in economic savings and highlight the actual dollar benefits (see Figure 1).

- Develop a more client-centered approach, listening to clients as they describe their perceptions of home energy issues and dialoguing with them to come up with creative solutions.

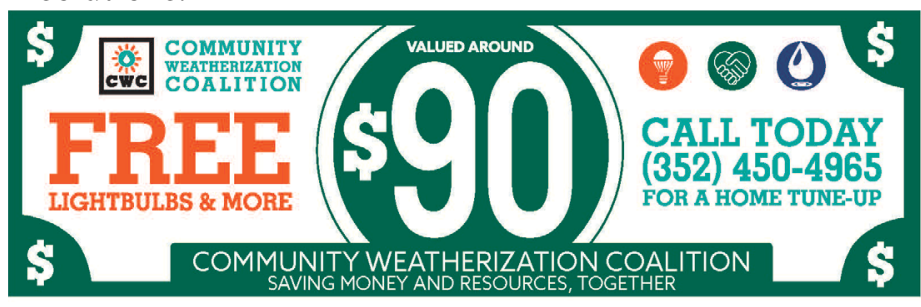

Figure 1.

\section{Marketing Material Development}

Marketing materials were designed by using the focus group results to build a new and stronger brand and identity. The CWC conducted an ad testing process of this design in which ads were shown to volunteers, clients and potential clients on three separate occasions. In response to the goals and ideas brought up during strategic planning meetings, the CWC also prioritized creating a promotional video. This video had multiple goals: to increase client 
recruitment, to increase volunteer enrollment, and to increase monetary donations to the program. Focus group participants had also stressed the importance of word-ofmouth advertising in the community, and yard signs were created to show the neighborhood that CWC was present (Figure 2).

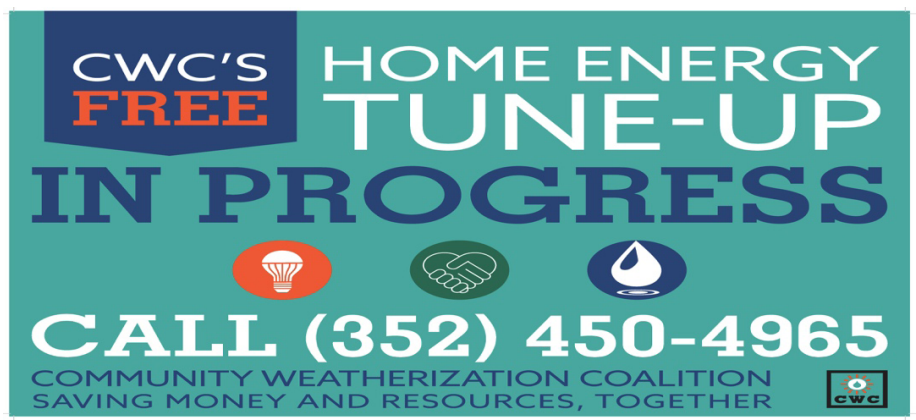

Figure 2.

\section{Volunteer Recruitment}

Focus groups with volunteers revealed what motivated them to participate, and these findings were incorporated into recruitment and training materials. Volunteers cited the following motivating factors:

- Making connections with interesting people, including other volunteers as well as clients,

- Making a tangible (if small) impact on global-scale problems,

- Answering a moral call to serve,

- Working for economic and environmental justice by helping the poor,

- Helping the local economy, and

- Finding the work interesting and always new.

The volunteer focus group research also revealed that the time commitment required to perform the audit as well as postaudit tasks (form entry, kit return, etc.) influenced their participation. Because volunteer time is so important to manage efficiently, the CWC developed a digital tablet form for the audits; they are intended to reduce the time it takes for data entry and reporting. The CWC also worked to increase the social benefits of volunteering with the program by increasing social events to build more camaraderie and connection among the team members.

\section{Conclusions: Reducing Barriers and Increasing Benefits to Improve Social Programs}

The CWC realized important benefits from social research designed to better understand the perspectives of clients, volunteers and partner organizations regarding our work in the community. Findings from the CBSM action research led to the implementation of changes in language, marketing materials and strategies, training content and approaches, volunteer engagement, procedures and materials used, partnership efforts and assessment of new program priorities.

Follow-up phone interviews with residents served revealed positive perceptions of the impacts of CWC tune-ups in knowledge gained, behavior change and satisfaction. Later evaluations showed that the improvements implemented using the insights from CBSM led to increased numbers of clients and volunteers as well as new forms of outreach to clients. The CBSM social research utilized by the CWC provides examples of valuable tools for listening to clients to improve program strategies and marketing. How clients and potential clients understand and interpret the communications from an organization can be just as important as the content that is presented. No matter how accurate or compelling external communication materials are, if potential clients interpret them differently, a program's enrollment or other metrics of impact can suffer.

Additional EDIS publications in this series will demonstrate how to establish a similar program in your community and will show how to measure the actual energy and water savings from these programs. For Extension educators who wish to know more about this project, the authors of this publication recommend that interested agents and community educators reach out to them for more information.

\section{References}

Abrahamse, W., Steg, L., Vlek, C., Rothengatter, T. (2005). A review of intervention studies aimed at household energy conservation. Journal of Environmental Psychology, 25(3), 273-291. https://doi.org/10.1016/j.jenvp.2005.08.002

McKenzie-Mohr, D., \& Smith, W. (1999). Fostering sustainable behavior: An introduction to community-based social marketing. Gabriola Island, B.C.: New Society. 
Reames, T. G. (2016). A community-based approach to low-income residential energy efficiency participation barriers, Local Environment, 21(12), 1449-1466. http:// dx.doi.org/10.1080/13549839.2015.1136995

Thomson, I., and Brain, R. (2016). A primer in communitybased social marketing. Cache Valley Transit District and Utah State Extension Service. https://digitalcommons.usu. edu/cgi/viewcontent.cgi? article $=2664 \&$ context $=$ extensi on_curall

US Department of Energy. (2017). Better buildings residential network community-based social marketing toolkit. https://www.energy.gov/sites/prod/files/2017/08/f35/bbrncommunity_based_social_marketing_toolkit_072617v2.pdf

\section{Appendix}

\section{For More Information}

The research reported here was funded through the American Public Power Association (APPA) DEED Program (Demonstration of Energy and Efficiency Developments) project entitled "Engaging Communities for Energy and Water Savings: Improving Measurement and Effectiveness of Energy/Water Audits for Low-Income Neighborhoods," through Gainesville Regional Utilities (GRU), to the Community Weatherization Coalition (CWC), May 1, 2016May 1, 2018. More details on the CMRB research activities conducted by the CWC, and advice on best practices for using social research, are provided in the following sources (available from the authors):

Ott, Emily. (2018). Saving Money and Resources, Together: Best Practices for Using Social Research to Improve Nonprofit Service Organizations.

Schmink, Marianne, Emily Ott, Lynn Jarrett, Anna Sampson, Matthew Bruce, and Alane Humrich. (2018). Engaging Communities for Energy and Water Savings: Improving Measurement and Effectiveness of Energy/Water Audits for Low-Income Neighborhoods.

Recorded webinar, April 30 2018, "Engaging Communities for Energy and Water Savings: Improving Measurement and Effectiveness of Energy/Water Audits for Low Income Neighborhoods," Community Weatherization Coalition (CWC) Gainesville Regional Utilities (GRU) University of Florida (UF), and We Are Neutral (WAN): https:// www.piecenter.com/wp-content/uploads/2018/05/CBSMWebinar-Presentation-DEED-FINAL-2.pdf.

\section{Publications in This Series}

Developing Extension Programming to Help Low-Income Families Save Money and Energy: The Community Weatherization Model.

Using Community-Based Social Marketing to Improve Energy Equity Programs.

Community-Based Home Energy Tune-up/Audit Programs: A Step-by-Step Guide to Creating and Implementing Energy Equity Programs in Your Community.

Options for Incorporating Energy Efficiency into Extension Programs: A Menu of Possibilities for Extension Energy Programming in Your Community. 